\title{
MECHANICAL CHARACTERIZATION OF HYBRID SANDWICH COMPOSITES WITH CONSTANT PU FOAM CORE DENSITY
}

\section{GIRISH V KULKARNI ${ }^{1} \&$ MOHANDAS K $\mathbf{N}^{2}$}

${ }^{1}$ Assistant Professor, Department of Mechanical Engineering, Ramaiah Institute of Technology Bengaluru, Karnataka, India

${ }^{2}$ Associate Professor, Department of Mechanical Engineering, Ramaiah Institute of Technology Bengaluru, Karnataka, India

\section{ABSTRACT}

Sandwich Composites finds its applications in varied fields of engineering since it is a promising material among many manmade structural materials. Further sandwich composites are class of materials that has several applications in areas such as aerospace, automobile and many consumer sectors. These materials are usually prepared by stacking two facings with an intermediate core, which is made of PU foam as one of the promising material for sandwich construction. The facings are strong and rigid while the core is weak and brittle in case of PU Foam. Since the sandwich composites behave differently due to directional properties, it is essential to understand their nature by making them undergo mechanical characterization especially static test.

In this study, sandwich composites made of Glass and Flax fiber based composite materials chosen along with PU Foam as the core. These materials are fabricated using vacuum bagging process subjected to mechanical characterization under flexural, flatwise and edge wise compression. The facings are made of different thickness however the prime focus is on understanding the behavior and nature of these sandwich structures under static loading. SIX specimens tested with different stacking sequence and the results show that Glass Fiber Sandwich Composites show higher resistance to loading under flat wise compression and GFFG-PU-GFFG sequence generated better edge wise compression resistance.

KEYWORDS: Sandwich Composites, Polyurethane, ASTM Standards, Flax, Glass Fiber, Vacuum Bagging Technique

Received: May 19, 2020; Accepted: Jun 09, 2020; Published: Jul 24, 2020; Paper Id.: IJMPERDJUN2020443

\section{INTRODUCTION}

Sandwich Composites are widely used in various fields of engineering because of its ability to provide high strength to weight ratio. A structural sandwich composite usually consists of two facings with an intermediate core. The core can be made of any material such as PU Foam, Honeycomb, PVC and custom 3D printed material with lesser infill in it. The facings are usually stiff and brittle / light in weight thick core material [1]. One of the primary reasons of using sandwich composites is to enable a better bending stiffness [2], it is evident that apart from above cited reasons, corrosion resistance is main factor why sandwich composites are preferred in aerospace industries [3]. Due to these two basic reasons, sandwich composites are highly preferred in aerospace, marine, and several consumer applications [4].

The sandwich structures are anisotropic in nature. It means their strength depends on the applied load. This would motivate us to design a composite in order to satisfy the application, provided we understand the anisotropic behaviour of the sandwich composite. They possess a considerably high stiffness and a high ratio of strength to weight. The exterior surface transfers load by bending and the core transfers load by shearing. [5-7]. There are several reasons for choosing sandwich material for a particular applications, based on the application, the facings 
are then decided, for a impact related fields Kevlar is highly preferred as compared to stiff applications involving glass fiber facings. This therefore calls for a proper understanding of material characteristics. In case of structural characteristics, physical and mechanical properties are essential. In such case, based on the loading conditions the mechanical reactions are decided and proper durability is ensure [8-11]. In relation to normal materials [12] for a laminate material of unit thickness, the sandwich structure stiffness is around 7 times followed by flexural strength around 3.5 times and weight with a very marginal increase by 1.04 times. This type of advantage enables composites to be used for various applications with very marginal increase in thickness. As mentioned earlier, due to its anisotropic nature, their strength varies based on the impact loading, based on this information; the composite materials can be fabricated using the available design of the material application in order to enable stiffness, strength, specific volume. Sandwich composites are widely used in case of applications involving stiffness as shown in Fig.1 and stated above, with marginal increase in thickness the stiffness increases by $4-7 \%$, with further increase in thickness by 4 times the stiffness increases by 37 times. With kind of strength enhancing capacity of sandwich composites enables it as an excellent player for different applications.

The most important ways to enhance the properties of a composite material is by fabricating them via vacuum bagging and in turn using Autoclave process to enhance the strength of composite material. Now based on the fabrication process, it is essential to identify the different testing process to find the best suitable composite material for a particular application. The most ideal testing process involved in composite materials especially sandwich structures are edge wise compression testing, flat wise compression testing and flexural testing process. Only after all these three tests are carried out, the functionality and feasibility of using sandwich panels are certified to different fields of engineering $[13,14]$. In case of flexural test process, the ASTM C393 standards are preferred for testing and the samples are fabricated based on the standards. Similarly, ASMT C365 - 94 is used to determine the flat wise compressive strength of composite materials, which helps us understand the nature of compressive strength of the sandwich panel in contrast with core material. Followed by this ASMT C364-94 is preferred for Edgewise compression strength of the sandwich panel to determine the core and facings combined strength and the types of modes of failure can be significantly determined. Further, several researchers have worked on identifying the nature of composite material and its behaviour based on stacking sequence and hybrid work of the facings. Combination of natural fibres and synthetic fibres usually looks promising since the nature of composite panels behave differently based on usage of different fibres and focusing on environmentally sustained sandwich panel. This research work focuses on stacking sequence of flax and glass fiber cloth with PU foam material as the core. The effect of strength, loading sequence and failure is discussed in this paper.

\section{Laminate (skin) Sandwich structure Thicker sandwich structure}
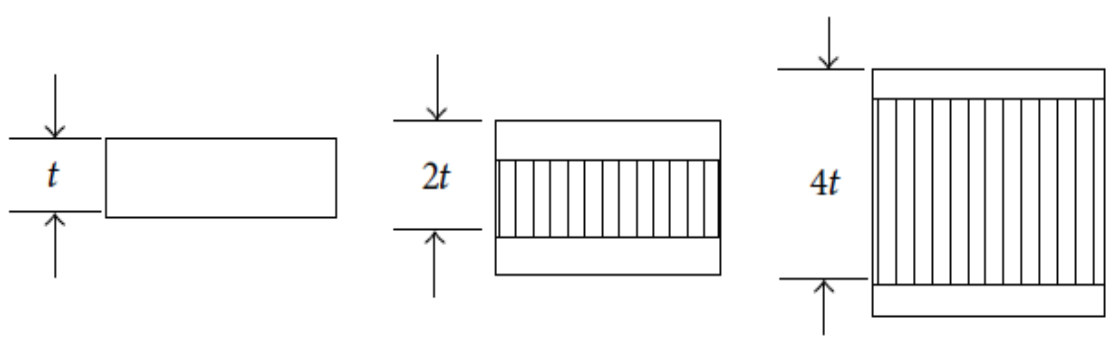

Figure 1: Structure of Different Types of Sandwich Laminates [12].

\section{EXPERIMENTAL METHODOLOGY}




\section{Sandwich Composite Fabrication}

The sandwich composites are manufactured by vacuum bagging technique. In this study Polyurethanes foam is used as the core. Plain woven Glass fibres with density of $2.10 \mathrm{~g} / \mathrm{cm}^{3}$ and tensile strength of $360 \mathrm{MPa}$ and Flax fibres, a natural cellulosic fibre from Flax plant with density of $1.4 \mathrm{~g} / \mathrm{cm} 3$ and tensile strength of 500MPa are used as the facing materials. Araldite epoxy resin with Aradur HY951 as the hardener is used as the matrix. In the fabrication of sandwich composite, a flat mould is chosen and is applied with polyvinyl fluoride and gel coat for easy removal and good surface quality. The glass fibre, flax fibres and Polyurethanes foam are cut to the required dimension of $325 \mathrm{~mm} \times 325 \mathrm{~mm}$ for different stacking sequences. For perfect vacuum mastic, sealant was surrounded around the mould. The fibre and resin are placed on the mould. Layers of fibres are added to get the required thickness. The entrapped air and excess resin between the fibre layers are removed by rollers or squeezers. The PU foam along with resin is placed on the fibre layers. The foam is pierced with a needle to have excess resin removal and sufficient bonding between the fibres and foam. The vacuum bagging technique is carried out for the fabrication of sandwich composite. The other side of the laminate is added similar to the procedure explained above. The sandwich composites are prepared for the different stacking sequences with $10 \mathrm{~mm}$ core thickness as shown in the Table 1. The sandwich panels are cut to the required size as per ASTM standards for mechanical characterization.

Table 1: Stacking Sequence of the Sandwich Panel for Glass - G; Flax - F

\begin{tabular}{|l|c|}
\hline \multicolumn{1}{|c|}{ Stacking Sequence } & Specimen Designation \\
\hline FFFF-PU-FFFF & C1 \\
\hline GGGG-PU-GGGG & C2 \\
\hline GFFG-PU-GFFG & C3 \\
\hline FGGF-PU-FGGF & C4 \\
\hline GGFF-PU-FFGG & C5 \\
\hline FFGG-PU-GGFF & C6 \\
\hline
\end{tabular}

\section{Flatwise Compression Testing of Sandwich Panel}

The flatwise compression test was carried out as per ASTM standard C365-94 for various sandwich panels as given Table 2. The test was carried out using a Mecmmesin Multi Test 10i machine with a constant loading rate of $4 \mathrm{~mm} / \mathrm{min}$. The flatwise compressive strength is found from the ultimate load.

The flatwise compressive strength is obtained from the equation

$$
\sigma=P / A
$$

Where, $\mathrm{P}$ is the ultimate load and $\mathrm{A}$ is the crossectional area of the specimen

The flatwise compressive modulus is obtained by the following equation

$$
\mathrm{E}=\mathrm{S} \times \mathrm{C} / \mathrm{A}
$$

Where, $\mathrm{S}$ is the slope of load-deflection curve, $\mathrm{C}$ is the core thickness and $\mathrm{A}$ is the cross sectional area of the facing panel subjected to compression.

The flatwise specimen and test arrangement are shown in Fig.2 (a) and (b). 


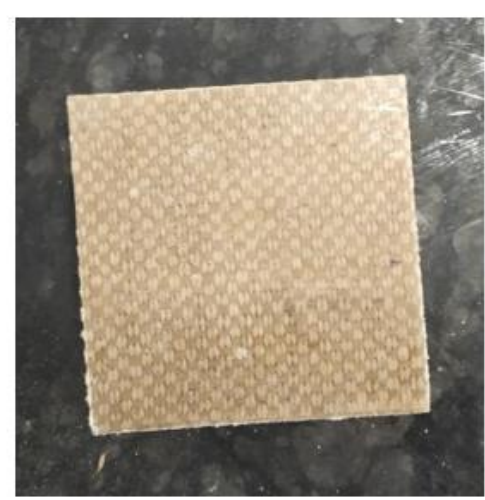

(a)

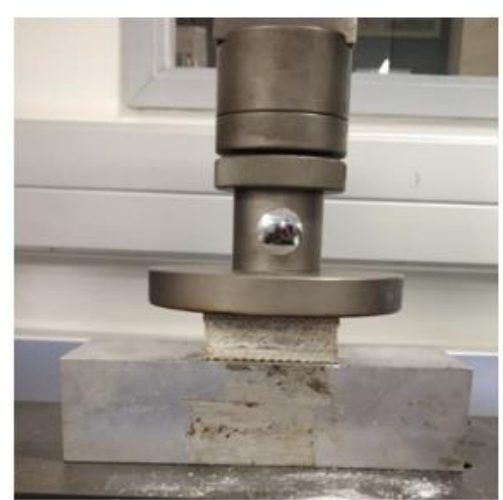

(b)

Figure 2: (a) Flatwise Compressive Test Specimen (b) Specimen Testing.

Table 2: Test Specimen Specifications for Flatwise Compression Test

\begin{tabular}{|l|c|c|c|c|}
\hline \multirow{2}{*}{ Stacking Sequences } & \multirow{2}{*}{ Specimen Designation } & \multicolumn{3}{c|}{ Dimensions } \\
\cline { 3 - 5 } & $\mathrm{C} 1$ & Length $(\mathbf{m m})$ & Width $(\mathbf{m m})$ & Thickness $(\mathbf{m m})$ \\
\hline FFFF-PU-FFFF & $\mathrm{C} 2$ & 50 & 50 & 17.340 \\
\hline GGGG-PU-GGGG & $\mathrm{C} 3$ & 50 & 50 & 11.760 \\
\hline GFFG-PU-GFFG & $\mathrm{C} 4$ & 50 & 50 & 14.230 \\
\hline FGGF-PU-FGGF & $\mathrm{C} 5$ & 50 & 50 & 15.358 \\
\hline GGFF-PU-FFGG & C6 & 50 & 50 & 15.350 \\
\hline FFGG-PU-GGFF & & &
\end{tabular}

\section{Edgewise Compression Testing of Sandwich Panel}

The edgewise compression test is carried out as per ASTM 364-94 standard. The test specimens were prepared as per the standards and specimen designations, specifications were given in the Table 3. The edge wise tests were carried out to analyse the face strength and to understand the phenomenon of crippling and wrinkling of the face sheet. The testing is carried out using a Mecmmesin Multi Test 10i machine with a constant loading rate of $4 \mathrm{~mm} / \mathrm{min}$. Edgewise compressive strength is obtained using the load vs deflection plot. Table 2 gives the dimensions of sandwich specimens for the edgewise compression testing. The edgewise test specimen and test arrangement are shown in Fig 3 (a) and (b).

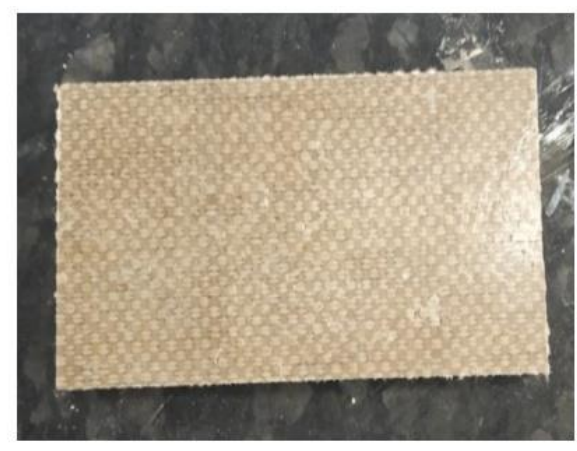

(a)

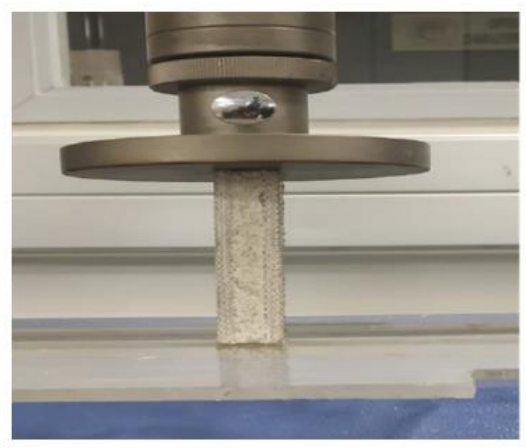

(b)

Figure 3: (a) Edgewise Compression Test Specimen (b) Specimen Testing. 
Table 3: Test Specimen Specifications for Edgewise Compression Test

\begin{tabular}{|l|c|c|c|c|}
\hline \multirow{2}{*}{ Stacking Sequences } & \multirow{2}{*}{ Specimen Designation } & \multicolumn{3}{c|}{ Dimensions } \\
\cline { 3 - 5 } & & Length (mm) & Width (mm) & Thickness (mm) \\
\hline FFFF-PU-FFFF & C1 & 90 & 50 & 17.340 \\
\hline GGGG-PU-GGGG & C2 & 90 & 50 & 11.760 \\
\hline GFFG-PU-GFFG & C3 & 90 & 50 & 14.230 \\
\hline FGGF-PU-FGGF & C4 & 90 & 50 & 16.358 \\
\hline GGFF-PU-FFGG & C5 & 90 & 50 & 15.830 \\
\hline FFGG-PU-GGFF & C6 & 90 & 50 & 15.350 \\
\hline
\end{tabular}

\section{Flexural Testing of Sandwich Panel}

The flexural testing is used to determine the core shear stiffness or strength, shear modulus and to analyse the sandwich beam deflection process. Three point bending test is carried out as per ASTM C393-94.The testing is carried out using a Mecmmesin Multi Test 10i machine with a constant loading rate of 5mm/min. The load is applied at mid span length of 100mm. the flexural test specimen, test arrangements are shown in Fig 4(a) and (b). The test specimen dimensions along with specimen designation are given in Table 4.

The face bending stress and core shear stress is given by the equation (3) and (4) as follows:

$$
\begin{aligned}
& \sigma_{b}=P L / 2(d+c) t b \\
& \tau=P /(d+c) b
\end{aligned}
$$

Where, $\mathrm{P}$ is the ultimate load, $\mathrm{L}$ is the span length, $\mathrm{b}$ is the sandwich width, $\mathrm{d}, \mathrm{c}$ and $\mathrm{t}$ are the thickness of sandwich, core and face sheet respectively

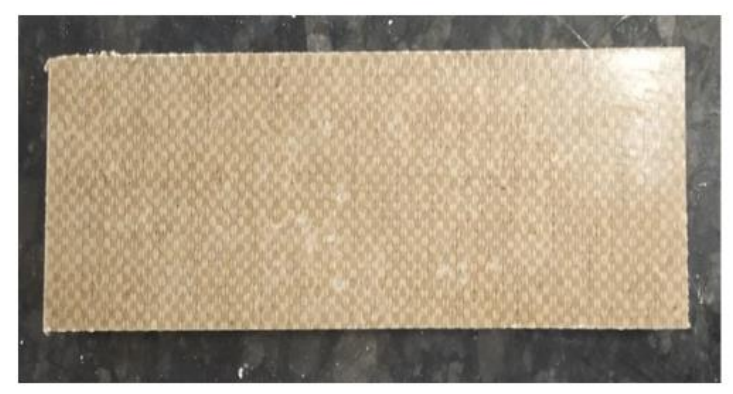

(a)

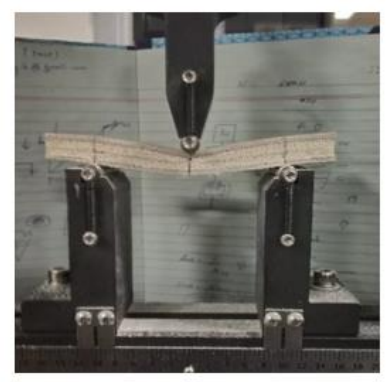

(b)

Figure 4: (a) Flexural Test Specimen (b) Specimen Testing.

Table 4: Test Specimen Specifications for Flexural Test

\begin{tabular}{|l|c|c|c|c|}
\hline \multirow{2}{*}{ Stacking Sequences } & \multirow{2}{*}{ Specimen Designation } & \multicolumn{3}{c|}{ Dimensions } \\
\cline { 3 - 5 } & & Length $(\mathbf{m m})$ & Width $(\mathbf{m m})$ & Thickness (mm) \\
\hline FFFF-PU-FFFF & C1 & 150 & 50 & 17.340 \\
\hline GGGG-PU-GGGG & C2 & 150 & 50 & 11.760 \\
\hline GFFG-PU-GFFG & C3 & 150 & 50 & 14.230 \\
\hline FGGF-PU-FGGF & C4 & 150 & 50 & 16.358 \\
\hline GGFF-PU-FFGG & C5 & 150 & 50 & 15.830 \\
\hline FFGG-PU-GGFF & C6 & 150 & 50 & 15.350 \\
\hline
\end{tabular}




\section{RESULTS AND DISCUSSION}

\section{Flatwise Compression Test}

The test was performed on all the six stacking sequence combination $(\mathrm{C} 1-\mathrm{C} 6)$. It was found based on the experimental process, the combination involving only Glass Fiber yielded better compression resistance since the effect of Glass has some significance on the overall compression strength. Further the effect of flatwise compression strength followed a similar patter shown in Fig 6. The load vs deflection curve moves linearly until the ultimate load is reached and further, the curve drops further. This is when the foam cell walls buckle and densification starts. Beyond this point, the curve steeply rises. The flatwise compressive modulus is obtained from equation 2 . Where $S$ is the slope, $t$ thickness, A cross sectional area of the facings of the flatwise specimen in consideration. The phenomenon shown in Fig. 6 is found in all the samples that were tested and the results are plotted as shown in Fig. 5.

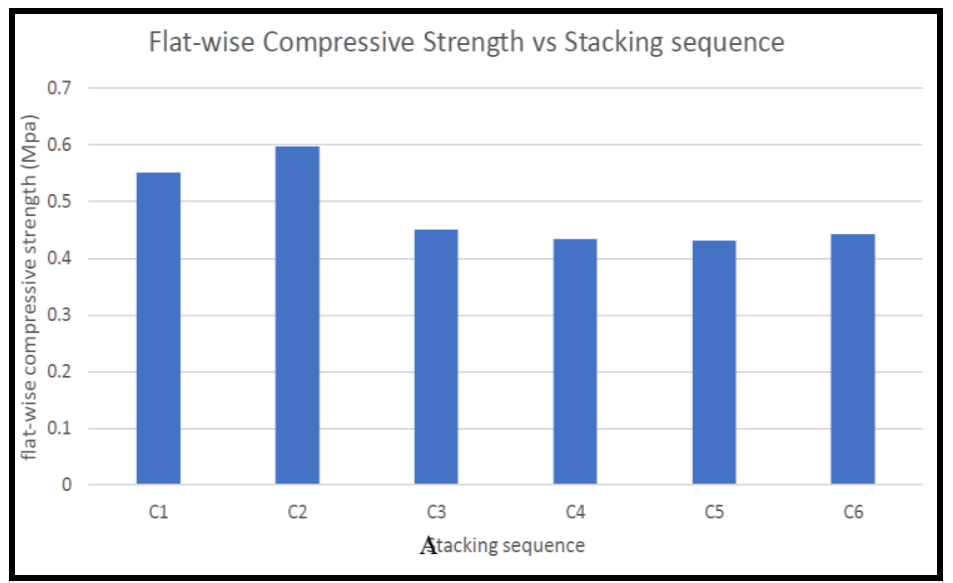

Figure 5: Stacking Sequence Effect on Flatwise Compression Test.

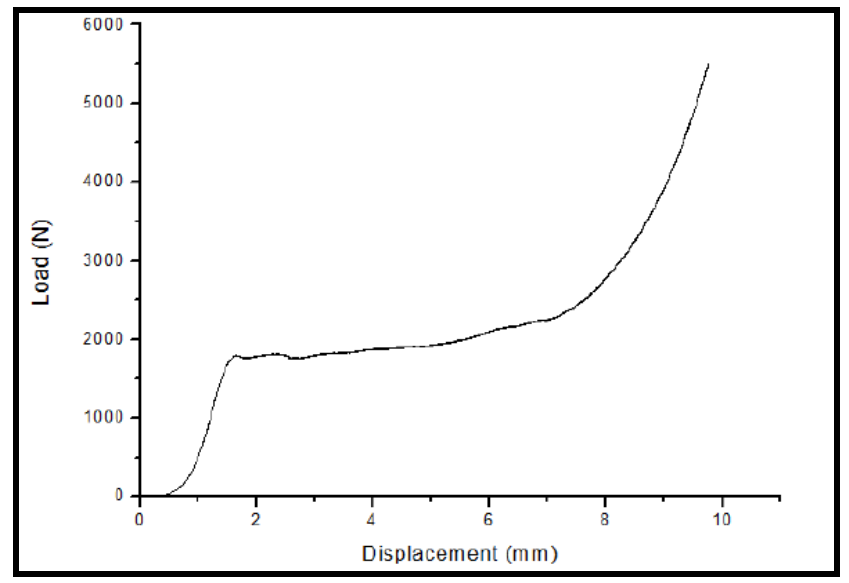

Figure 6: Trend of Load Vs Deflection Cure for Flatwise Compression Strength.

Table 5: Flatwise Compressive Modulus

\begin{tabular}{|c|c|}
\hline Specimen Code & Flat-wise Compressive Modulus (mpa) \\
\hline C1 & 4.459 \\
\hline C2 & 5.459 \\
\hline C3 & 2.966 \\
\hline C4 & 1.976 \\
\hline C5 & 1.771 \\
\hline C6 & 1.686 \\
\hline
\end{tabular}




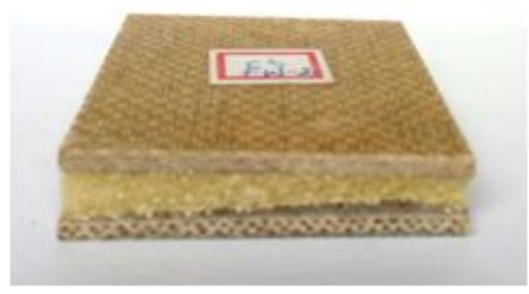

C3FW2

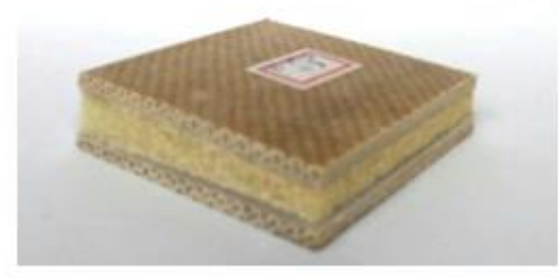

C6FW3

Figure 7: Flatwise Compression of C3 and C6 Samples.

\section{Edgewise Compression Test}

The Edgewise compression test was performed on dimensions as shown in Table 3. It was found that there were several types of failure attributed to the test and the trend of the failure is shown in Fig.8. It clearly shows that different failure modes are visible and are listed in Table 6.

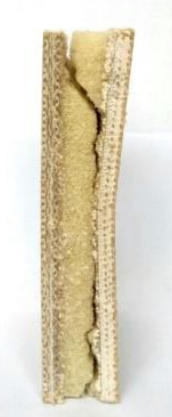

C1E W

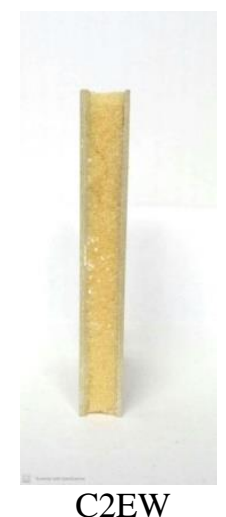

C3EW

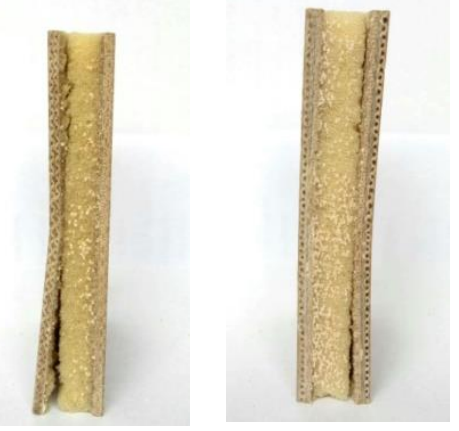

C4EW

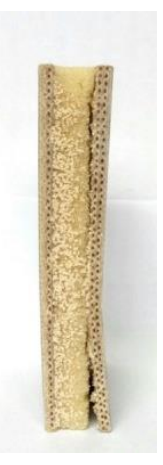

C5EW

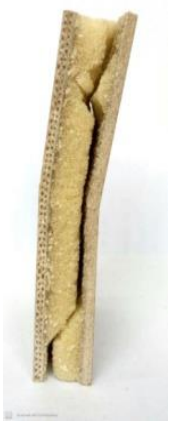

C6EW

Figure 8: Edgewise Compression Damage Mechanism.

Table 6: Damage Mechanism and Ultimate Load under Edgewise Compressive Compression

\begin{tabular}{|c|c|c|c|}
\hline Specimen Code & Ultimate Load (n) & $\begin{array}{c}\text { Facing Edge-wise Compressive } \\
\text { Strength (MPa) }\end{array}$ & Mode of Failure \\
\hline C1 & 9988.315 & 1.1098 & III \\
\hline C2 & 5389.632 & 0.5980 & IV \\
\hline C3 & 11485.750 & 1.2760 & II, \\
\hline C4 & 8643.002 & 0.960 & I, II \\
\hline C5 & 9475.097 & 1.082 & II, IV \\
\hline C6 & 8765.085 & 0.974 & I, III \\
\hline
\end{tabular}

Based on the above test results, it is found that $\mathrm{C} 3$ had highest edgewise compressive strength, while $\mathrm{C} 2$ had the lowest Edgewise compressive Strength. This was found to be due to lacking in bonding strength between glass fiber and PU foam interface. Further the lamina thickness was $0.25 \mathrm{~mm}$ as compared to Flax which was around $0.3 \mathrm{~mm}$ for each layer.

\section{Flexural Test / Three Point Bend-Test}

The three-point bend test is an essential test that needs to be performed on a sandwich panel to determine the face bending stress and core shear stress. These parameters help researchers to decide the amount of stress the facings can take and the amount of stress in turn elucidate them to choose the sandwich composite for different fields of engineering. The test was 
performed as per ASTM C393 - 94. The load displacement curve was plotted and ultimate load was found out, which was used to calculate face bending stress and core shear strength as in Table 7.

Table 7: Three Point Bending Test Results

\begin{tabular}{|c|c|c|c|}
\hline Specimen Code & Ultimate Load (N) & $\begin{array}{c}\text { Face Bending } \\
\text { Stress(MPa) }\end{array}$ & $\begin{array}{c}\text { Core Shear Stress } \\
(\mathbf{M P a})\end{array}$ \\
\hline C1 & 1149.214 & 17.180 & 0.84000 \\
\hline C2 & 642.704 & 50.345 & 0.59072 \\
\hline C3 & 1101.995 & 32.219 & 0.90946 \\
\hline C4 & 928.0214 & 16.612 & 0.70416 \\
\hline C5 & 1232.225 & 24.348 & 0.95410 \\
\hline C6 & 1124.860 & 24.835 & 0.88746 \\
\hline
\end{tabular}

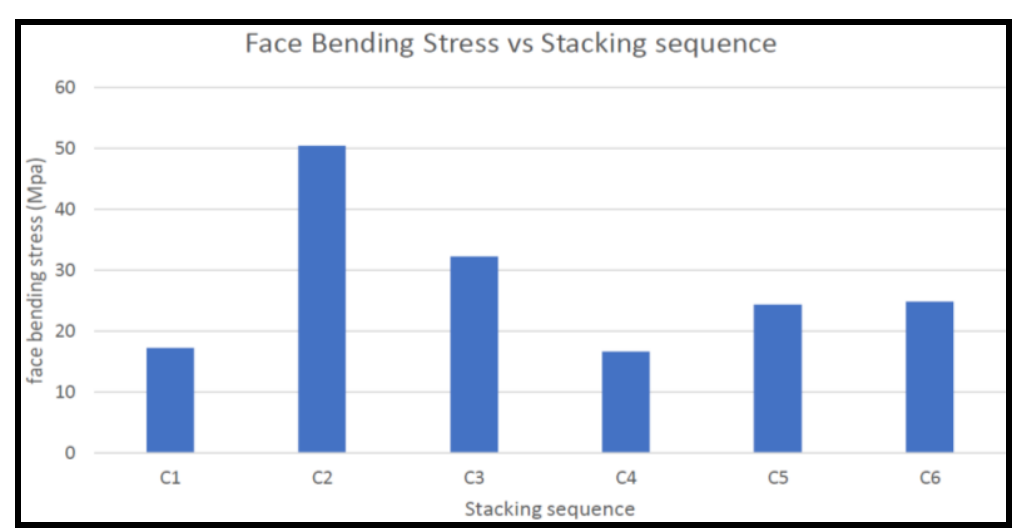

Figure 9: Face Bending Stress v/s Stacking Sequence.

It was observed that $\mathrm{C} 2$ specimen consisting of pure glass fibre (face sheet) showed best face bending stress, higher tensile strength of glass fibre is responsible for this behaviour. It was also observed that bottom face sheet of $\mathrm{C} 2$ specimen does not completely break even when load exceed ultimate load. This behaviour can be attributed to ductility of glass fibre. But in case of $\mathrm{C} 1$ which consisted of pure flax fibres in face sheet broke in two post ultimate load, this shows that flax fibres turn brittle when the epoxy resin sets. Further, C5 Specimen showed better core shear stress as the combination that was adopted was GGFF-PU-FFGG, this was due to presence of glass fiber at the facings which resulted in better strength as compared to Flax at the outer surface.

\section{CONCLUSIONS}

Sandwich structures are one of the most rapidly emerging classes in the construction of various composite materials. However, the performance of these materials depends on their construction sequence. It is found that with variation of facing material the performance of these materials changes. Further, with a combination of Flax and Glass fiber cloth, the results showed promising in case of flatwise compression, the samples $\mathrm{C} 2$ and $\mathrm{C} 1$ showed better properties as compared to C3, C4, C5 this was mainly due to placing of facings of flax either at the top layer or at the intermediate layer. With pure Glass the results were higher in case of flatwise compressions test.

In case of Edgewise compression the samples $\mathrm{C} 3, \mathrm{C} 1, \mathrm{C} 5$ showed excellent results as compared to $\mathrm{C} 2$, this is a clear indication that presence of glass and flax as hybrid increased the edgewise load carrying of the sample. However, with pure glass the edgewise compression strength drastically reduced.

In case of Flexural Compression test, the sample $\mathrm{C} 2$ and $\mathrm{C} 3$ displayed excellent results due to the presence of the glass at the facings and at right proportions. With altering Glass and Flax at equal proportions and at altering sequence did 
not show any change in values, this sequence is of importance as presence of equal proportion has no increase or decrease in face bending stress.

\section{REFERENCES}

1. American Society of Testing and Materials. ASTM standard terminology of structural sandwich constructions (C274-99). West Conshohocken, PA: ASTM International 1999.

2. Belouettar, S, Abbadi, A, Azari, Z, Belouettar, R, Freres, P. Experimental investigation of static and fatigue behaviour of composite honeycomb materials using four point bending tests. Composite Structures 2008; 87(3), pp 265-273.

3. Russo, A, Zuccarello, B. Experimental and numerical evaluation of the mechanical behaviour of GFRP sandwich panels. Composite Structures 2007; 81, pp 575-586.

4. Ismail, Mahmud Rasheed, Z. A. A. A. Ali, and Muhannad Al-Waily. "Delamination damage effect on buckling behavior of woven reinforcement composite materials plate." International Journal of Mechanical \& Mechatronics Engineering IJMMEIJENS 18.05 (2018): 83-93.

5. Keller, T. Material tailored use of FRP composites in bridge and building construction, Swiss Federal Institute of Technology Lausanne, Switzerland, 2006.

6. F. C. Campbell, Structural Composite Materials, ASM International, Novelty, Ohio, 2010.

7. S. Ochelski and T. Niezgoda, "Kompozytowekonstrukcjepochtaniająceenergięuderzenia," PrzegladdMechaniczny, vol. 1, pp. 21-28, 2007

8. A. Muc and R. Nogowczyk, "Formyzniszczeniakonstrukcjisandwiczowych $z$ okładzinamiwykonanymi $z$ kompozytów," Composites, Vol. 5, No. 4, pp. 31-36, 2005

9. A. I. Boczkowska, Kompozyty, OficynaWydawniczaPolitechnikiWarszawskiej, Warszawa, Poland, 2003.

10. Jaafar, Ali Munther, and Muhannad Al-Waily. "Calculation of elastic deformation under the influence of high velocity impact on composite plate structures." International Journal of Energy and Environment 10.6 (2019): 359-371.

11. W. Kr'olikowski, PolimeroweKompozytyKonstrukcyjne, WydawnictwoNaukowePWN, Warszawa, Poland, 2012.

12. H. Leda, KompozytyPolimerowe $z$ W'oknamiCiaglymi: Wytwarzanie, Wła'sciwo'sci, Stosowanie, WydawnictwoPolitechnikiPozna'nskiej, Pozna'n, Poland, 2006.

13. Maythraza, M., et al. "Vibration analysis of honeycomb sandwich panel in spacecraft structure." International Journal of Mechanical and Production Engineering Research and Development 8.3 (2018): 849-860.

14. D. Zuchowska, PolimeryKonstrukcyjne, WydawnictwoNaukowoTechniczne,Warszawa, Poland, 2000.

15. F. C. Campbell, Structural Composite Materials, ASM International, Novelty, Ohio, 2010.

16. BEEDU, RAJENDRA. "Application of grey relational analysis for multi response optimization of process parameters in drilling of carbon-basalt hybrid composite. "International Journal of Mechanical and Production Engineering Research and Development (IJMPERD) 10. 1, Feb 2020, 295-304.

17. S. Ochelski and T. Niezgoda, "Kompozytowekonstrukcjepochtaniajaceenergięuderzenia," PrzegladMechaniczny, Vol. 1, pp. 21-28, 2007.

18. ASTM, "Standard test method for flatwise compressive properties of sandwich cores," ASTM Standard C 365-03, American $\begin{array}{lllll}\text { Society } & \text { for } & \text { Testing } & \text { Materials, }\end{array}$ 

